\title{
Children’s Primary Dental Treatment Needs According to Their Parents
}

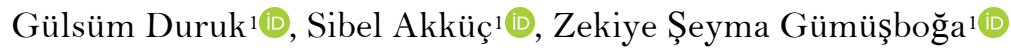

${ }^{1}$ Department of Pediatric Dentistry, Faculty of Dentistry, Inonu University, Malatya, Turkey.

Correspondence: Gulsum Duruk DDS, Ph.D., Department of Pediatric Dentistry, Faculty of Dentistry, Inonu University, 44280, Malatya, Turkey. E-mail: durukgulsum@yahoo.com

Academic Editor: Ana Maria Gondim Valença

Received: 10 September 2020 / Review: 12 November 2020 / Accepted: 24 November 2020

How to cite: Duruk G, Akküç S, Gümüşboğa ZS. Children’s primary dental treatment needs according to their parents. Pesqui Bras Odontopediatria Clín Integr. 2021; 21 :e0201. https://doi.org/10.1590/pboci.2021.059

\begin{abstract}
Objective: To determine the children's primary dental treatment needs reported by the parents and pediatric dentists. Material and Methods: 125 children (36 girls and 89 boys) and their parents participated in this study. The children's decayed-missing-filled teeth/teeth surfaces scores were recorded. A questionnaire about their children's primary dental treatment needs was conducted with the parents. Shapiro-Wilk test was used to test the normality of the data. Kruskal-Wallis test was used to compare the clinical findings according to the categorical variables. The Chi-Square test was used to compare the categorical data. Also, multiple linear regression analysis was performed to determine the effect of some variables on children's dmft/DMFT scores. The significance level was accepted as $\mathrm{p}<0.05$. Results: The average age of the children who participated in the study was $7.59 \pm 2.36$ years. The main reason for applying to the paedodontics clinic was dental caries (38.4\%), followed by dental pain (33.6\%). As for the primary dental treatment needs, $28 \%$ of the parents said they needed dental filling, while $19.2 \%$ said they needed orthodontic treatment. According to the pediatric dentists, while the treatment rate of dental caries was $47.2 \%$ as the primary treatment need, it was only $4.8 \%$ for the orthodontic treatments. Conclusion: Turkish children who were admitted to paedodontics clinics were too old and dental caries and dental pain were the most common reasons for these visits to the clinics. The children's needs for primary treatment varied according to parents and pediatric dentists. There is a need for more comprehensive studies about the subject.
\end{abstract}

Keywords: Dental Health Services; Dental Care for Children; Child; Parents. 


\section{Introduction}

Dental caries is one of the most common chronic diseases in pediatric patients [1]. The prevalence of early childhood caries (ECC) is gradually increasing in developing countries such as Turkey [2]. Growthdevelopment retardation due to pain, eating and sleep disorders, the presence of a constant focus of infection in the mouth, the fact that they lead to caries in permanent dentition, and the adverse psychological effect resulting from aesthetic anxiety are among the problems brought about by ECC [3].

It is recommended by the American Academy of Pediatric Dentistry (AAPD) [4] and American Academy of Pediatrics (AAP) [5] that parents should take their children to the first dental examination at the age of 12 months at the latest to prevent the formation and adverse effects of ECC in children. Nevertheless, Mika et al. [6], Daou et al. [7], and Olatosi et al. [8] reported that the average age of the first dental examination in children was $3.79 \pm 1.82$ years, $4.24 \pm 1.35$ years, and $7.9 \pm 3.7$ years, respectively, which reveals that the first dental examination is conducted too late for preventive and interceptive treatments in various populations. There are many studies reporting that the reasons for the first dental examination are pain and caries [6-10]. Furthermore, it is observed in the studies that parents take their children to the dentist only when they feel pain and discomfort [11,12], which is caused by reasons such as geographical factors, parents' low education levels, and low awareness of the need for dental treatment [10,13].

Admission to the dental clinic at an early age is important so that the child can be included in the preventive application program at an early age. Among the goals of WHO in the 21 st century, it is targeted that $80 \%$ of children under 6 years old will have teeth without caries and that the mean $\mathrm{dmft} / \mathrm{DMFT}$ will be 1.5 in children under 12 years old [14]. In the data of the last epidemiological study conducted in the Turkish population by Gokalp et al. [15] in 2010, dmft/DMFT scores were $3.7 \pm 3.9$ in the age group of 5 years, $1.9 \pm$ 2.2 in the age group of 12 years, and $2.3 \pm 2.5$ in the age group of 15 years.

In many studies in the literature, the average age of children, dmft/DMFT scores, oral health attitudes and behaviors, the reasons for admission to the first dental examination, and parents' sociodemographic status were evaluated [6-13]. However, the need for primary dental treatment from the parents' perspective and the primary treatment needs from the pediatric dentists' perspective have not been compared to the best of our knowledge. In this study, in addition to evaluating the reasons for admission of children who visited the paedodontics clinic for the first time, the age of admission, and the dental treatment needs, it was aimed to compare the children's primary dental treatment needs stated by the parents and pediatric dentists and to determine the level of awareness of the parents about the primary dental treatment needs of their children.

The null hypotheses of this study are (i) children's first visit to a paedodontic clinic is quite late compared to AAPD guidelines, (ii) most children apply to the clinic with complaints of dental caries and dental pain, and (iii) most parents are not aware of what their children's primary dental treatment need is.

\section{Material and Methods}

Ethical Clearance

Ethical approval was obtained from Ethical Committee of Inönü University (ethic number: 2020/79). All procedures performed in studies involving human participants were in accordance with the ethical 
standards of the institutional and/or national research committee and with the 1964 Helsinki declaration and its later amendments or comparable ethical standards. The written informed consent was obtained from the parents before the examination.

\section{Study Design and Sample}

This cross-sectional study was performed in the Faculty of Dentistry, Department of Paedodontics, at Inönü University, Turkey. One hundred twenty-five children (36 girls, 89 boys) and their parents, all volunteers, participated in this study. The families whose children visited the paedodontics clinic for the first time took part in the survey from January 2020 to February 2020. These children had never been to a pedodontics clinic before. The children who had systemic diseases and who had no family consent were excluded from the study.

The calculated post-hoc power (1-beta) based on this test is 0.929 , considering type I error (alfa) of 0.05 , sample sizes of 125 , effect size of 0.31 for the percentage of applicants to a paedodontics clinic with dental caries and/or dental pain and two-sided alternative hypothesis $\left(\mathrm{H}_{1}\right)$.

\section{Questionnaire}

A new questionnaire about children's dental problems and their primary dental treatment needs was developed for the current study. Firstly, a literature search in Turkish and English was carried out to look for guidelines by using the keywords "parent”, “dental visit”, "first appointment”, “dental treatment requirement”, "dental treatment needs", and "pediatric dentistry". Then a questionnaire was compiled from the relevant sources.

The content adequacy of the questionnaire was examined by experts in order to assess the clarity of the wording of the items prior to the main study. The questions were sent to three pediatric dentists. Based on comments from these experts, some items were added. Then, the final questionnaire was tested by two pediatric dentists to see whether the questions were understandable and within the conceptual framework. Finally, the questionnaire was sent to a Turkish language expert for linguistic validity, and the questionnaire was finalized in this stage. The reliability of the questionnaire was tested on 15 parents. They filled in the questionnaire twice, at 14-day intervals, and the 15-paired questionnaires were analyzed for test-retest reliability using the Cohen's kappa test.

\section{Data Collection}

All clinical examinations were performed by two experienced pediatric dentists (SA and ZŞG). Also, a radiographic examination was performed when necessary for diagnosis, panoramic and periapical radiographs were taken in pediatric patients adhering to the ALARA principles. The decayed-missing-filled teeth (dmft/DMFT) and decayed-missing-filled teeth surfaces (dmfs/DMFS) were recorded. The extraction of the primary teeth due to the physiological root resorption was not recorded as a missing tooth. The diagnosis was based on two factors: clinical and radiographic features. 
The examiners were trained and calibrated to measure the clinical (dmft/DMFT, dmfs/DMFS) and the radiological (periapical x-ray evaluation) parameters prior to the study.

The Cohen's kappa coefficients were calculated according to the evaluated results of the clinical and radiological examination for determining the inter- and intra-rater agreement. To carry out the Cohen's kappa, two specialists performed an oral examination of randomly selected 15 children twice, with a 1-week interval.

\section{Statistical Analysis}

The data obtained were analyzed using IBM SPSS V22 (SPSS Inc., Chicago, IL, USA). Test-retest reliability was determined with Cohen's kappa. Shapiro-Wilk test was used to test the normality of the data. Kruskal-Wallis test was used to compare the clinical findings according to the categorical variables. ChiSquare test was used to compare the categorical data. Multiple linear regression analysis was also performed to determine the effect of some variables on children's dmft/DMFT scores. The significance level was accepted as $\mathrm{p}<0.05$.

\section{Results}

For the reliability of the questionnaire, Cohen's Kappa was calculated as 0.84. The children who participated in the study were $7.59 \pm 2.36$ years (range 2 to 12). The percentages of parental education level and the children's oral health-related attitudes and behavior and oral clinical examination findings are presented in Table 1. The children's mean dmft/DMFT scores were 7.26 \pm 4.46 . The examiners' Kappa scores for inter- and intra-rater agreement after both oral examinations ranged from 0.97 to 0.99 .

Table 1. Sociodemographic status of the parents, and the children's oral health-related behaviors and the findings of oral clinical examination.

\begin{tabular}{ccc}
\hline \multicolumn{1}{c}{ Variables } & N (\%) \\
\hline Parent & Maternal Education & \\
Primary School & $49(39.2)$ \\
Secondary School & $19(15.2)$ \\
High School & $32(25.6)$ \\
University & $20(16.0)$ \\
Postgraduate & $5(4.0)$ \\
Paternal Education & \\
Primary School & $27(21.6)$ \\
Secondary School & $23(18.4)$ \\
High School & $32(25.6)$ \\
University & $34(27.2)$ \\
Postgraduate & $9(7.2)$ \\
Dentition Period & $30(24.0)$ \\
Primary & $69(55.2)$ \\
Mixed & $26(20.8)$ \\
Permanent & \\
Whether there was a Dental Visit Before & $81(64.8)$ \\
Yes & $44(35.2)$ \\
No & \\
The Frequency of Dental Visits & $44(35.2)$ \\
The First Time & $68(54.4)$ \\
When there is a Complaint of Pain & $11(7.2)$ \\
Once a Year & $4(3.2)$ \\
Twice a Year & $12(9.6)$ \\
Tooth Brushing Frequency & $51(40.8)$ \\
Never &
\end{tabular}




\begin{tabular}{cc} 
Once a Day & $46(36.8)$ \\
Twice a Day & $16(12.8)$ \\
The Findings of the Children's Oral Clinical Examination & Mean (SD) \\
The Number of Caries Teeth & $6.29(4.41)$ \\
The Number of Missing Teeth & $0.30(0.83)$ \\
The Number of Filling Teeth & $0.68(1.44)$ \\
The dmft/DMFT & $7.26(4.46)$ \\
The dmfs/DMFS & $15.5911 .05)$ \\
\hline
\end{tabular}

The reasons for children to apply to the paedodontics clinic are presented in Table 2. The most frequent reason for applying to the paedodontics clinic was due to dental caries (38.4\%), followed by dental pain $(33.6 \%)$.

Table 2. The reasons for children to apply to the pediatric dental clinic.

\begin{tabular}{|c|c|}
\hline Questions & N (\%) \\
\hline Check-up & $26(20.8)$ \\
\hline Tooth Discoloration & $\mathrm{O}(0.0)$ \\
\hline Dental Caries & $48(38.4)$ \\
\hline Dental Pain & $42(33.6)$ \\
\hline Gum Pain & $2(1.6)$ \\
\hline Joint Pain & $\mathrm{o}(0.0)$ \\
\hline Swelling of the Gums & $7(5.6)$ \\
\hline Swelling of the Face & $\mathrm{o}(0.0)$ \\
\hline Misalignment & $20(16.0)$ \\
\hline Mobility of Teeth & $4(3.2)$ \\
\hline Halitosis & $6(4.8)$ \\
\hline Bruxism & $1(0.8)$ \\
\hline Dental Trauma & $4(3.2)$ \\
\hline Injuries of Mouth/Lip & $0(0.0)$ \\
\hline Food Impaction & $1(0.8)$ \\
\hline
\end{tabular}

In clinical examination, $12 \%$ of the children needed emergency dental treatment, $81.6 \%$ needed restorative treatment, $20 \%$ needed endodontic treatment, 34.4\% needed surgical treatment, $21 \%$ needed periodontal treatment, and $17.6 \%$ needed orthodontic treatment.

According to the families and pediatric dentists, comparisons of the children's primary dental treatment needs are presented in Table 3 . As the primary dental treatment need, $28 \%$ of the parents said that it was dental filling, while $19.2 \%$ said it was orthodontic treatment. According to the pediatric dentists, while the treatment of dental caries was $47.2 \%$ as the primary dental treatment need, $4.8 \%$ was the orthodontic treatment. According to the pediatric dentists, orthodontic treatment was the primary dental treatment need for only $16.7 \%$ of the children, whose parents defined the primary treatment need for them as orthodontic treatment.

The mean dmft/DMFT and dmfs/DMFS scores of the children in terms of the primary treatment needs from the parents' perspective are presented in Table 4. The children whose parents defined their children's primary treatment need as "medication should be prescribed" and "teeth should be straighted with braces" had the lowest dmft/DMFT and dmfs/DMFS scores.

The parental education variables and some variables about the children's oral health-related attitudes and behavior determined in the regression model explained $1 \%$ of the children's dmft/DMFT scores. The "whether there was a dentist visit before" variable has the most explanatory power $(\beta=0.168)$ (Table 5). 
Table 3. Comparisons of the children's primary dental treatment need according to their parents and the pediatric dentists.

\begin{tabular}{|c|c|c|c|c|c|c|c|c|c|c|}
\hline \multirow[b]{2}{*}{ According to the Children's Families } & \multicolumn{10}{|c|}{ According to the Pediatric Dentists } \\
\hline & $\begin{array}{c}\text { Elimination } \\
\text { of Pain } \\
\mathrm{N}(\%)\end{array}$ & $\begin{array}{c}\text { Drug } \\
\text { Prescription } \\
\text { N (\%) }\end{array}$ & $\begin{array}{c}\text { Tooth } \\
\text { Extraction } \\
\mathrm{N}(\%)\end{array}$ & $\begin{array}{c}\text { Root Canal } \\
\text { Treatment } \\
\mathrm{N}(\%)\end{array}$ & $\begin{array}{l}\text { Scaling and Root } \\
\text { Planning } \\
\mathrm{N}(\%)\end{array}$ & $\begin{array}{c}\text { Restorative } \\
\text { Treatment } \\
\mathrm{N}(\%)\end{array}$ & $\begin{array}{c}\text { Orthodontic } \\
\text { Treatment } \\
\mathrm{N}(\%)\end{array}$ & $\begin{array}{c}\text { Preventive } \\
\text { Treatment } \\
\mathrm{N}(\%)\end{array}$ & Maintenance & $\begin{array}{l}\text { Total } \\
\text { N (\%) }\end{array}$ \\
\hline Pain should be Relieved & $0(0.0)$ & $1(5.3)$ & $1(5.3)$ & $11(57.9)$ & $1(5.3)$ & $5(26.3)$ & $0(0.0)$ & $0(0.0)$ & $0(0.0)$ & $19(15.2)$ \\
\hline Medication should be Prescribed & $0(0.0)$ & $0(0.0)$ & $0(0.0)$ & $0(0.0)$ & $0(0.0)$ & $1(100.0)$ & $0(0.0)$ & $0(0.0)$ & $0(0.0)$ & $1(0.8)$ \\
\hline Tooth should be Extracted & $0(0.0)$ & $0(0.0)$ & $9(64.3)$ & $0(0.0)$ & $1(7.1)$ & $4(28.6)$ & $0(0.0)$ & $0(0.0)$ & $0(0.0)$ & $14(11.2)$ \\
\hline Root Canal Treatment should be done & $0(0.0)$ & $0(0.0)$ & $3(30.0)$ & $4(40.0)$ & $0(0.0)$ & $3(30.0)$ & $0(0.0)$ & $0(0.0)$ & $0(0.0)$ & $10(8.0)$ \\
\hline Scaling and Root Planning should be done & $0(0.0)$ & $0(0.0)$ & $1(50.0)$ & $0(0.0)$ & $0(0.0)$ & $1(50.0)$ & $0(0.0)$ & $0(0.0)$ & $0(0.0)$ & $2(1.6)$ \\
\hline Caries should be Cleaned and Filled & $0(0.0)$ & $1(2.9)$ & $3(8.6)$ & $5(14.3)$ & $1(2.9)$ & $25(71.4)$ & $0(0.0)$ & $0(0.0)$ & $0(0.0)$ & $35(28.0)$ \\
\hline Teeth should be Straightened with Braces & $0(0.0)$ & $0(0.0)$ & $2(8.3)$ & $0(0.0)$ & $3(12.5)$ & $13(54.2)$ & $4(16.7)$ & $2(8.3)$ & $0(0.0)$ & $24(19.2)$ \\
\hline Fluoride Gel should be applied & $0(0.0)$ & $0(0.0)$ & $1(50.0)$ & $0(0.0)$ & $0(0.0)$ & $0(0.0)$ & $1(50.0)$ & $0(0.0)$ & $0(0.0)$ & $2(1.6)$ \\
\hline I do not know & $0(0.0)$ & $0(0.0)$ & $5(27.8)$ & $2(11.1)$ & $1(5.6)$ & $7(38.9)$ & $1(5.6)$ & $2(11.1)$ & $0(0.0)$ & $18(14.4)$ \\
\hline Total & $0(0.0)$ & $2(1.6)$ & $25(20.0)$ & $22(17.6)$ & $7(5.6)$ & $59(47.2)$ & $6(4.8)$ & $4(3.2)$ & $\mathrm{O}(0.0)$ & $125(100.0)$ \\
\hline
\end{tabular}

Values in the same row and subtable not sharing the same subscript are significantly different at $\mathrm{p}<0.05$ in the two-sided test of equality for column proportions based on $\mathrm{z}$-tests with APA-style subscripts. ChiSquare; $\mathrm{p}<0.001$.

Table 4. The mean dmft/DMFT and dmfs/DMFS scores of children in terms of the primary dental treatment need from the parents' perspective.

\begin{tabular}{|c|c|c|c|}
\hline According to Children's Parents & $\mathbf{N}(\%)$ & $\begin{array}{c}\text { dmft/DMFT } \\
\text { Mean (SD) }\end{array}$ & $\begin{array}{c}\text { dmfs/DMFS (Mean and SD) } \\
\text { Mean (SD) }\end{array}$ \\
\hline Pain should be Relieved & $19(15.2)$ & $8.84(5.080)$ & $17.32(11.01)$ \\
\hline Medication should be Prescribed & $1(0.8)$ & $4(0.0)$ & $7(0.0)$ \\
\hline Tooth should be Extracted & $14(11.2)$ & $7.29(4.07)$ & $16.07(7.85)$ \\
\hline Root Canal Treatment should be done & $10(8.0)$ & $8.40(4.35)$ & $15.30(9.15)$ \\
\hline Scaling and Root Planning should be done & $2(1.6)$ & $8.50(2.12)$ & $18(2.83)$ \\
\hline Caries should be Cleaned and Filled & $35(28)$ & $8.86(3.91)^{\mathrm{a}}$ & $20.34(11.60)^{\mathrm{a}}$ \\
\hline Teeth should be Straightened with Braces & $24(19.2)$ & $4.63(4.02)^{\mathrm{b}}$ & $9.54(10.01)^{b}$ \\
\hline Fluoride Gel should be Applied & $2(1.6)$ & $6.50(9.19)$ & $12(16.97)$ \\
\hline I do not know & $18(14.4)$ & $5.50(3.79)$ & $13(11.56)$ \\
\hline Total & $125(100.0)$ & $7.26(4.46)$ & $15.59(11.05)$ \\
\hline *p-value & & 0.021 & 0.020 \\
\hline
\end{tabular}

*Kruskal Wallis; a,bThe numbers containing different letters are significantly different from each other. 
Table 5. Explanation of the $\mathrm{dmft} / \mathrm{DMFT}$ score with multiple linear regression analysis.

\begin{tabular}{|c|c|c|c|c|c|}
\hline \multicolumn{6}{|c|}{ dmft/DMFT Score } \\
\hline & B & SE B & $\beta$ & $\mathrm{t}$ & p-value* \\
\hline (Constant) & 12.284 & 1.570 & & 7.825 & $<0.001$ \\
\hline Maternal education & -0.762 & 0.393 & -0.214 & -1.940 & 0.055 \\
\hline Paternal education & -0.152 & 0.379 & -0.043 & -0.400 & 0.690 \\
\hline Whether there was a dentist visit before & 1.560 & 1.447 & 0.168 & 1.078 & 0.283 \\
\hline Tooth brushing frequency & -0.401 & 0.467 & -0.076 & -0.859 & 0.392 \\
\hline The frequency of dental visits & -0.785 & 0.985 & -0.126 & -0.796 & 0.427 \\
\hline $\begin{array}{l}\text { The primary dental treatment that the child should receive } \\
\text { according to the family }\end{array}$ & -0.343 & 0.157 & -0.196 & -2.180 & 0.031 \\
\hline \multirow[t]{2}{*}{ Model Summary } & $\mathrm{R}$ & $\mathrm{R}_{2}$ & \multicolumn{2}{|c|}{ Adjusted $\mathrm{R}_{2}$} & SEE \\
\hline & 0.380 & 0.144 & \multicolumn{2}{|c|}{0.101} & 4.226 \\
\hline
\end{tabular}

*Multiple linear regression analysis; Dependent variable: $\mathrm{dmft}$ /DMFT score.

\section{Discussion}

In this study, the reasons for the children's admission to the paedodontics clinic and to what extent the families had knowledge of their children's needs for primary dental treatment were investigated. Dental caries is a preventable disease when all necessary measures are taken. Therefore, it is important that families are conscious and that the child is included in a preventive program related to dental health.

In this study, the average age of 125 children who visited the paedodontics clinic for the first time was found to be $7.59 \pm 2.36$ years. The AAPD [4] and AAP [5] recommend that the age of the first dental examination in children should be 6-12 months. Mika et al. [6] reported that the average age in 320 children who visited the dentist for the first time was $3.79 \pm 1.82$ years, Daou et al. [7] reported that the average age in 220 children who visited the paedodontics clinic for the first time was $4.24 \pm 1.35$ years, and Olatosi et al. [8] reported that the average age in 1551 children who visited the paedodontics clinic for the first time was $7.9 \pm$ 3.7 years. In this study, the average age of the children who applied to the paedodontics clinic for the first time (7.59 \pm 2.36 years) was well above the age recommended by the AAPD $[4]$ and AAP [5]. This result also revealed parents' lack of knowledge about the age of taking their children to pediatric dentists. Moreover, $64.8 \%$ of the pediatric patients who were admitted to the paedodontics clinic for the first time were referred to the pediatric dental clinic by the general dentist who had examined them previously.

According to the results of this study, the reason for admission to the pediatrics clinic was mostly dental caries (38.4\%), followed by dental pain (33.6\%), check-ups (20.8\%), and misalignment (16\%). Similar to our study, Daou et al. [7] reported that the reasons for admission to the first dental examination were mostly dental caries $(50.9 \%)$ and dental pain $(29.5 \%)$. Nevertheless, in the literature, there are also studies reporting that children were admitted to the first dental examination mostly due to dental pain by $33.1 \%$ [8], 71.5\% [9], and $37.3 \%[10]$.

According to the questions, they answered, $54.4 \%$ of the parents stated that they took their children to the dentist only when they had pain, which is compatible with many studies in the literature [11-13]. Thus, our hypothesis stating that the rate of admission to the clinic with the complaints of dental caries and dental pain would be high was confirmed. Furthermore, the results of our study showed that $12 \%$ of the children, who were admitted, needed emergency treatment, $81.6 \%$ of them needed restorative treatment, $20 \%$ of them needed endodontic treatment, $34.4 \%$ of them needed surgical treatment (tooth extraction), $21 \%$ of them needed periodontal treatment, and $17.6 \%$ of them needed orthodontic treatment.

When the primary treatment need was asked, according to the parents, "the removal of caries," "the alignment of the teeth with a dental brace," and "pain relief" were among the most preferred options, 
respectively. On the other hand, $15 \%$ of the parents had no idea about what their children's primary treatment need was.

Although the parents of $28 \%$ of the children stated that caries should be removed and filled, $47.2 \%$ of the children needed restorative treatment from pediatric dentists' perspective. The results showed that the parents who applied to the pediatrics clinic were not sufficiently aware of caries in the mouth of their children. The asymptomatic onset of caries, the pain caused by caries when cavitation occurs, or when the carious lesion approaches the pulp. Therefore, its late perception by parents and children is among the reasons for the situation.

Furthermore, while "the alignment of the teeth with a dental brace" was the primary treatment need according to the parents of $24(19.2 \%)$ children, only $4(16.7 \%)$ of these children primarily needed orthodontic treatment according to pediatric dentists. The remaining $54.2 \%$ and $12.5 \%$ of them primarily needed restorative treatment and periodontal treatment, respectively. Moreover, $2 \%$ of them needed only preventive treatment. When the children's primary dental treatment need was asked, the parents chose the orthodontic treatment option at a higher rate than it should be because the crowded teeth in children during the transition from primary dentition to permanent dentition worried parents aesthetically.

The dmft/DMFT and dmfs/DMFS scores of the children whose parents indicated orthodontic treatment as the primary dental treatment need were lower than the other children. However, this average is higher than the study evaluating the oral health status of the children in the Turkish population conducted by Gokalp et al. [15] and the WHO's 21st-century goals [14]. There was a statistically significant difference in the dmft/DMFT and dmfs/DMFS scores among the children whose parents indicated "the alignment of the teeth with a dental brace" and "the removal of caries" as the primary treatment option. Actually, the children, whose parents considered "the alignment of the teeth with a dental brace" as the primary treatment, had poor oral health. This statistical significance supports our null hypothesis indicating that "most parents are not aware of what their children's primary treatment need is."

According to the multiple regression analysis, the variable "Whether there was a dentist visit before" was the strongest effect on the dmft/DMFT score. Based on this information obtained, it is observed how important it is for parents to make their first visit to the dentist when the first primary tooth erupts. Then, the child will have regular dentist visits and be included in the preventive dental application programs at an early age.

While this is the first study to compare children's primary treatment needs from parents and pediatric dentists' perspective, which constitutes the strength of the study, the low number of participants and the lack of interventions to raise awareness of parents were the limitations of our study.

\section{Conclusion}

The age of the first admission to the paedodontics clinic in the pediatric patients was higher than the age recommended by the AAPD and AAP, and the most frequently encountered reasons for admission were dental caries and dental pain. Parents usually took their children to the pediatric dentists when they had dental pain, and they were not sufficiently aware of their children's dental treatment needs. Children's primary treatment needs varied according to parents and pediatric dentists.

There is a need for more comprehensive studies on this issue with larger sample sizes. It is essential for caries-free generations to organize educational programs in which parents and pediatric dentists cooperate. 


\section{Authors' Contributions}

\begin{tabular}{|c|c|c|}
\hline GD & (D) https://orcid.org/0000-0002-6756-6637 & $\begin{array}{l}\text { Conceptualization, Methodology, Formal Analysis, Investigation, Writing - Original Draft and } \\
\text { Writing - Review and Editing. }\end{array}$ \\
\hline SA & https://orcid.org/0000-0003-4504-6988 & Investigation, Resources and Writing - Review and Editing. \\
\hline ZSG & https://orcid.org/0000-0002-6744-7830 & Investigation and Writing - Review and Editing. \\
\hline
\end{tabular}

\section{Financial Support}

None.

\section{Conflict of Interest}

The authors declare no conflicts of interest.

\section{Data Availability}

The data used to support the findings of this study can be made available upon request to the corresponding author.

\section{Acknowledgments}

The authors wish to thank all participants for their invaluable contribution to this study.

\section{References}

[1] American Academy of Pediatric Dentistry. Guideline on periodicity of examination, preventive dental services, anticipatory guidance/counseling, and oral treatment for infants, children, and adolescents. Pediatr Dent 2013; 35(5):E148-156.

[2] Bagramian RA, Garcia-Godoy F, Volpe AR. The global increase in dental caries. A pending public health crisis. Am J Dent 2009; $22(1): 3-8$.

[3] Filstrup SL, Briskie D, da Fonseca M, Lawrence L, Wandera A, Inglehart MR. Early childhood caries and quality of life: child and parent perspectives. Pediatr Dent 2003; 25(5):431-40.

[4] American Academy of Pediatric Dentistry. Clinical Affairs Committee - Infant Oral Health S: Guideline on Infant Oral Health Care. Pediatr Dent 2012; 34(5):e148-e152.

[5] Section on Pediatric Dentistry and Oral Health. Preventive oral health intervention for pediatricians. Pediatrics 2008; 122(6):1387-94. https://doi.org/10.1542/peds.2008-2577

[6] Mika A, Mitus-Kenig M, Zeglen A, Drapella-Gasior D, Rutkowska K, Josko-Ochojska J. The child's first dental visit. Age, reasons, oral health status and dental treatment needs among children in Southern Poland. Eur J Paediatr Dent 2018; 19(4):265-70. https://doi.org/10.23804/ejpd.2018.19.04.3

[7] Daou MH, Eden E, El Osta N. Age and reasons of the first dental visit of children in Lebanon. J Med Liban 2016; 64(1):18-22. https://doi.org/10.12816/0023827

[8] Olatosi OO, Onyejaka NK, Oyapero A, Ashaolu JF, Abe A. Age and reasons for first dental visit among children in Lagos, Nigeria. Niger Postgrad Med J 2019; 26(3):158-63. https://doi.org/10.4103/npmj.npmj_60_19

[9] Murshid EZ. Children's ages and reasons for receiving their first dental visit in a Saudi community. Saudi Dent J 2016; 28(3):142-7. https://doi.org/10.1016/j.sdentj.2015.12.003

[10] Alshahrani NF, Alshahrani ANA, Alahmari MA, Almanie AM, Alosbi AM, Togoo RA. First dental visit: Age, reason, and experiences of Saudi children. Eur J Dent 2018; 12(4):579-84. https://doi.org/10.4103/ejd.ejd_426_17

[11] Agostini FG, Flaitz CM, Hicks MJ. Dental emergencies in a university-based pediatric dentistry postgraduate outpatient clinic: a retrospective study. ASDC J Dent Child 2001; 68(5-6):316-21.

[12] Sakai VT, Magalhaes AC, Pessan JP, Silva SM, Machado MA. Urgency treatment profile of o to 15 year-old children assisted at urgency dental service from Bauru Dental School, University of São Paulo. J Appl Oral Sci 2005; 13(4):340-4. https://doi.org/10.1590/s1678-77572005000400005

[13] Hussein AS, Abu-Hassan MI, Schroth RJ, Ghanim A. Parent's perception on the importance of their children's first dental visit: A cross-sectional pilot study in Malaysia. JOR 2013; 1(1):17-25. https://doi.org/10.12816/0012189

[14] Petersen PE. Changing oral health profiles of children in Central and Eastern Europe - Challenges for the 21 st century. IC Digest 2003; 2:12-3.

[15] Gokalp SG, Dogan BG, Tekcicek MT, Berberoglu A, Unluer S. National survey of oral health status of children and adults in Turkey. Community Dent Health 2010; 27(1):12-7. 